\title{
Parental knowledge and care-seeking practices towards pediatric ear infections: a study from Iraq
}

\author{
Aqil Mohammad Daher ${ }^{1}$, Abdulla Alnakshabandi ${ }^{2}$, Khaled Hashim Sultan ${ }^{3}$, Basim Atallah Al-Abdely ${ }^{4}$, \\ Allya Mohammad $\mathrm{Ali}^{5}$ \\ ${ }^{1}$ Department of Community Medicine, School of Medicine, International Medical University, Kuala Lumpur, Malaysia \\ ${ }^{2}$ Department of ENT, Dr. Sulaiman Al-Habib Hospital, Dubai, UAE \\ ${ }^{3}$ Department of Pediatrics, Bin Sina Teaching Hospital, Mosul, Iraq \\ ${ }^{4}$ Department of Pediatrics, Fallujah Teaching Hospital for Maternity and Childhood, Fallujah, Iraq \\ ${ }^{5}$ Department of Pediatrics, Al Kanssa Teaching Hospital, Mosul, Iraq
}

\begin{tabular}{l} 
Article Info \\
\hline Article history: \\
Received Jun 4, 2021 \\
Revised Nov 24, 2021 \\
Accepted Dec 2, 2021 \\
\hline
\end{tabular}

Keywords:

Care-seeking

Ear infection

Knowledge

Paediatric

Practice

Smoking status

\begin{abstract}
An ear infection (EI) is one of the most common pediatric illnesses. This study aimed to assess parental knowledge, care-seeking practices, and factors associated with them. A cross-sectional study involved a sample of parents attending hospitals in three selected cities in Iraq. Data were collected with a questionnaire composed of three parts: i) Sociodemographic characteristics, ii) Questions related to knowledge of symptoms, risk factors, and complications of an EI, and iii) Questions related to care-seeking practices. The mean age of respondents was $34.99( \pm 9.85)$ years. Females made up $58.90 \%$ of the sample. More than half reported holding tertiary education. Most participants showed satisfactory knowledge of EI symptoms $(88.10 \%)$ and proper practices of seeking medical attention from a doctor or other medic $(95.80 \%)$. Respondents with tertiary education had higher odds of having satisfactory knowledge (OR 4.63, 95\% CI 1.18-18.19) and proper care-seeking practices (OR 14.96, 95\% CI 1.12-28.80) than those with primary education and below. Current smokers had higher odds of having unsatisfactory knowledge (OR $0.12,95 \%$ CI $0.02-0.70$ ) than non-smokers. In conclusion, respondents had sufficient knowledge and care-seeking practices. Educational level was associated with adequate knowledge and care-seeking practices, and former smoking status was associated with unsatisfactory knowledge.
\end{abstract}

This is an open access article under the $\underline{C C B Y-S A}$ license.

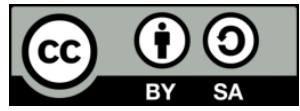

\section{Corresponding Author:}

Aqil Mohammad Daher

Department of Community Medicine, School of Medicine, International Medical University

Bukit Jalil, 57000 Kuala Lumpur, Malaysia

Email: aqi1702001@yahoo.com

\section{INTRODUCTION}

An ear infection (EI) is one of the most common health problems and a major cause of acquired hearing loss in pediatric patients [1]. By three years of age, about $80 \%$ of children would have developed at least one episode of an EI [2]. EIs are highly prevalent in children due to the anatomy of the middle ear [3]. An untreated EI carries a high risk of severe consequences. Hearing loss, as the most unfavorable outcome, impacts the quality of life of both children and their family members [4]-[7]. Existing literature has explored a spectrum of risk factors associated with an EI, ranging from child gender and atopic diseases to family smoking habits, living conditions and accessibility to health care [8]-[12]. Additionally, the outcomes of EIs are associated with parental knowledge about predisposing factors, healthy ear care practices, complications of ear infection, and care-seeking practices. 
Previous studies revealed a relationship between poor knowledge and negative attitudes towards EIs, and a higher prevalence of these infections [13]. Low knowledge level among young parents was associated with the delayed care-seeking practices for patients suffering from chronic suppurative otitis media [14]. A recent study reported an association of parental care-seeking behavior with the socioeconomic status of the family and the perceived severity of the disease [15]. Parents with negative beliefs, perception of stigma and lack of knowledge were more likely to use home remedies rather than seek medical care for their children [16].

In Iraq, the literature on parental behavior towards pediatric EIs is scarce. As such, little known about parental knowledge and care seeking behavior which might affect the outcomes of pediatric ear infections. Thus, we undertook this study to assess the extent of knowledge and care-seeking practices among Iraqi parents of children with EIs. Results of this study may help healthcare professionals to address the gaps in preventing unfavorable EI outcomes and informs policies, design, and implementation of appropriate evidence-based interventions.

\section{RESEARCH METHOD}

\subsection{Study design}

This was a cross-sectional study that involved parents of children aged between one and ten years who attended three selected teaching hospitals in three major cities in Iraq. Parents accompanying their children to the pediatric clinics of the teaching hospitals, whether for the first or subsequent follow-up visits, were selected randomly. Selected parents were briefed about the purpose of the study and ensured that participation is voluntary and no personal data, if any, would be disclosed to a third party.

\subsection{Study tool}

A self-administered questionnaire was used to collect the data. The questionnaire was composed of three parts: i) Sociodemographic characteristics, ii) Knowledge about symptoms, predisposing factors, and complications of EI, iii) Preventive and care-seeking practices. The response options for knowledge questions were 'yes', 'no', and 'do not know', while the response options for questions on preventive and health-seeking practices were 'yes' and 'no'. All participants provided informed consent prior to participation.

\subsection{Statistical analyses}

Data were entered and analyzed using SPSS version 24 software. Descriptive statistics were calculated and presented as frequencies and percentages for categorical variables and mean (SD) for numerical variables. For the knowledge scale, the correct answers were given one point, while the incorrect and 'do not know' answers were given zero points. The answers to 14 questions related to EI symptoms, risk factors and complications were summed together to derive the knowledge score. Respondents who answered correctly to $50 \%$ and above of the questions were considered having satisfactory knowledge. The proper care-seeking practice was defined as a practice of seeking medical attention from a doctor or medical assistant (nurse). Logistic regression was used to determine factors associated with knowledge and careseeking practices.

\section{RESULTS AND DISCUSSION}

Table 1 shows the demographic characteristics of respondents. Out of 278 distributed forms, 239 were completed, yielding a response rate of $83 \%$. The mean age of the respondents was $34.99( \pm 9.85)$ years. Females made up $58.90 \%$ of the sample. More than half $(55.93 \%)$ were holding tertiary education, and less than $10 \%$ reported no formal education. The vast majority $(95.30 \%)$ were living with a spouse. Over half $(51.27 \%)$ were working, and about one-third (32.63\%) were housewives. Most of the respondents were nonsmokers $(81.36 \%)$, had average income in comparison to their peers $(75.85 \%)$, and owned a car $(60.43 \%)$.

Table 2 shows the distribution of answers to the questions. The majority of respondents endorsed the following symptoms of EI: earache, rubbing ear, sleeping disturbances, fever, and ear discharge. In terms of the possible EI complications, hearing loss was the most frequently $(72.27 \%)$ endorsed option, followed by learning difficulties (54.62\%), speech problems (43.31\%), and the spread of infection to the brain (29.24\%). The respondents' ability to correctly identify the cardinal symptoms of EI, namely pain and discharge, might be attributed to their previous experience of managing childhood infections and their relatively high educational level. However, other studies found lower levels of knowledge about childhood EI [13]-[17]. Such discrepancy in findings might be due to the difference in settings, study populations and criteria to measure the level of knowledge in each study, as well as methodological strengths and limitations. Only a small proportion $(8.37 \%)$ believed there were no complications of EI. Taking a shower or swimming, resulting in ear wetting, was the most frequently endorsed risk factor $(88.28 \%)$, followed by scratching ears 
with sharp objects $(78.99 \%)$, using unsterilized examination set by the doctor $(60.04 \%)$, cleaning ears with ear pads $(62.18 \%)$ and cold weather $(60.05 \%)$. Overall, $88.10 \%$ of participants showed satisfactory knowledge of ear infection symptoms. This finding is in tandem with some of the recent studies [18].

Table 1. Characteristics of respondents

\begin{tabular}{llcc}
\hline & Characteristic & $\mathrm{n}$ & $\%$ \\
\hline Dwelling & Mosul & 108 & 45.57 \\
& Falluja & 65 & 27.43 \\
Gender & Baghdad-Hila & 64 & 27.00 \\
& Male & 97 & 41.10 \\
Education & Female & 139 & 58.90 \\
& No formal education & 23 & 9.75 \\
& Primary & 46 & 19.49 \\
& Secondary & 35 & 14.83 \\
Occupation & Tertiary & 132 & 55.93 \\
& No working & 25 & 10.59 \\
& Working & 121 & 51.27 \\
Smoking status & Housewife & 77 & 32.63 \\
& Student & 13 & 5.51 \\
Income group & Non-smoker & 192 & 81.36 \\
& Former smoker & 11 & 4.66 \\
& Current smoker & 33 & 13.98 \\
Marital status & Below average & 21 & 8.90 \\
Car possession & Average & 179 & 75.85 \\
& Above average & 36 & 15.25 \\
Age years mean $( \pm$ SD) & Living alone & 11 & 4.70 \\
Number of children below 10 years mean $( \pm$ SD) & Living with a spouse & 223 & 95.30 \\
& & 93 & 39.57 \\
& No & 142 & 60.43 \\
& Yes & $1.63( \pm 1.01)$ & \\
\hline
\end{tabular}

Table 2. Parental knowledge of symptoms, risk factors and complications of EI in children

\begin{tabular}{|c|c|c|c|c|c|}
\hline Symptoms & $\begin{array}{c}\text { Endorsed with } \\
\text { yes } \\
\text { n }(\%) \\
\end{array}$ & Cause/ Risk factors & $\begin{array}{l}\text { Endorsed with yes } \\
\mathrm{n}(\%)\end{array}$ & Complications & $\begin{array}{c}\text { Endorsed with yes } \\
\mathrm{n}(\%)\end{array}$ \\
\hline Earache* & $215(90.34)$ & $\begin{array}{l}\text { Taking shower or swimming } \\
\text { (water trapped in the ear) * }\end{array}$ & $211(88.28)$ & Hearing loss* & $172(72.27)$ \\
\hline Rubbing ear* & $209(87.45)$ & $\begin{array}{l}\text { Scratching ear with a sharp } \\
\text { object* }\end{array}$ & 188 (78.99) & Learning difficulties & $130(54.62)$ \\
\hline $\begin{array}{l}\text { Sleeping } \\
\text { disturbance* }\end{array}$ & $197(82.43)$ & $\begin{array}{l}\text { Using unsterilized examination } \\
\text { set* }^{*}\end{array}$ & $165(69.04)$ & Speech problems & $82(34.31)$ \\
\hline Fever* & $168(70.29)$ & Cleaning ear with pads & $148(62.18)$ & Spread to the brain* & $69(29.24)$ \\
\hline Ear discharge* & $145(60.67)$ & Cold weather & $144(60.5)$ & Nothing & $20(8.37)$ \\
\hline $\begin{array}{l}\text { Hearing } \\
\text { difficulty* }\end{array}$ & $135(56.72)$ & Ear wax* & $123(51.46)$ & & \\
\hline Running nose & $67(28.03)$ & Respiratory allergic disease* & $111(46.64)$ & & \\
\hline Cough & $36(15.13)$ & Family member with EI & $97(40.93)$ & & \\
\hline Vomiting & $23(9.66)$ & Smoking at home* & $60(25.53)$ & & \\
\hline Diarrhea & $19(7.95)$ & Vaccination & $34(14.29)$ & & \\
\hline
\end{tabular}

*used in the calculation of knowledge score

Table 3 depicts responses related to preventive and care-seeking practices. Cleaning an ear with medical pads $(73.22 \%)$ was the most frequently endorsed option for EI prevention, followed by preventing water from entering the ear $(45.76 \%)$ and avoiding smoking at home $(38.91 \%)$. The prevailing majority of participants reported that if their child had an EI, they would seek medical attention from the doctor $(93.72 \%)$, and only a small proportion reported that they would seek help from any medic at the nearest clinic (7.53\%). Overall, $95.80 \%$ showed proper care-seeking practices.

The high proportion of parents willing to seek proper medical care for their children might be attributed to the availability of healthcare services. Previous studies have documented the relationship between service availability and health-seeking behavior [19], [20]. Another possible explanation is that traditional medicine does not play a significant role in Iraqi society. Before the American occupation of Iraq in 2003, the national healthcare system witnessed spectacular advancement [21]. Fortunately, the healthcare system has retained its capacity to cope with population primary healthcare needs. 
Table 3. Parental preventive and care-seeking practices

\begin{tabular}{lclc}
\hline \multicolumn{1}{c}{ Prevention } & $\begin{array}{c}\text { Endorsed with yes } \\
\mathrm{n}(\%)\end{array}$ & \multicolumn{1}{c}{ Care-seeking practice } & $\begin{array}{c}\text { Endorsed with yes } \\
\mathrm{n}(\%)\end{array}$ \\
\hline Clean ears with ear pads & $175(73.22)$ & Take the child to the doctor* & $224(93.72)$ \\
Prevent wetting of ear & $108(45.76)$ & Buy medicine and self-treat & $47(19.67)$ \\
Do not smoke at home & $93(38.91)$ & Take the child to the nearest medic* & $18(7.53)$ \\
Read about ear care & $53(22.18)$ & Do nothing, wait and see & $9(3.77)$ \\
\hline
\end{tabular}

*Used in the calculation of care-seeking practice score

Table 4. Factors associated with parental knowledge about EI in children

\begin{tabular}{|c|c|c|c|c|c|}
\hline \multicolumn{2}{|c|}{ Knowledge } & \multicolumn{2}{|l|}{ Crude } & \multicolumn{2}{|l|}{ Adjusted } \\
\hline & & OR $(95 \% \mathrm{CI})$ & p-value & OR $(95 \% \mathrm{CI})$ & p-value \\
\hline \multirow[t]{3}{*}{ Age } & $<30$ years old & 1 & & 1 & 0.374 \\
\hline & $30-40$ years old & $1.25(0.42,3.72)$ & 0.686 & $0.79(0.22,2.81)$ & 0.717 \\
\hline & $>40$ years old & $0.65(0.22,1.87)$ & 0.421 & $0.36(0.08,1.58)$ & 0.174 \\
\hline \multirow[t]{2}{*}{ Gender } & Male & 1 & & 1 & \\
\hline & Female & $1.19(0.52,2.7)$ & 0.681 & $3.35(0.59,19.04)$ & 0.173 \\
\hline \multirow[t]{2}{*}{ Marital status } & Living alone & 1 & & 1 & \\
\hline & Living with a spouse & $2.65(0.51,13.89)$ & 0.248 & $3.01(0.5,17.97)$ & 0.228 \\
\hline \multirow[t]{3}{*}{ Education } & Primary and below & $0(0,0)$ & 0.154 & 1 & \\
\hline & Secondary & $2.39(0.87,6.61)$ & 0.093 & $3.52(0.91,13.65)$ & 0.069 \\
\hline & Tertiary & $2.89(0.88,9.47)$ & 0.079 & $4.63(1.18,18.19)$ & 0.028 \\
\hline \multirow[t]{3}{*}{ Occupation } & Not working & 1 & & 1 & \\
\hline & Housewife & $0.62(0.16,2.41)$ & 0.493 & $0.14(0.02,1.08)$ & 0.059 \\
\hline & Working & $0.95(0.25,3.59)$ & 0.935 & $1.54(0.34,7.05)$ & 0.579 \\
\hline \multicolumn{2}{|c|}{ Number of children below 10 years } & $0.93(0.63,1.38)$ & & $0.86(0.55,1.35)$ & 0.518 \\
\hline \multirow[t]{3}{*}{ Smoking status } & Non-smoker & 1 & & 1 & \\
\hline & Former smoker & $0.79(0.25,2.49)$ & 0.683 & $0.7(0.15,3.21)$ & 0.647 \\
\hline & Current smoker & $0.31(0.08,1.27)$ & 0.104 & $0.12(0.02,0.7)$ & 0.019 \\
\hline \multirow[t]{3}{*}{ Income group } & Below average & 1 & & 1 & \\
\hline & Average & $2(0.61,6.6)$ & 0.255 & $2.83(0.63,12.66)$ & 0.173 \\
\hline & Above average & $1.65(0.36,7.47)$ & 0.518 & $1.09(0.15,7.88)$ & 0.935 \\
\hline \multirow[t]{3}{*}{ Dwelling } & Mosul & 1 & & 1 & \\
\hline & Falluja & $0.94(0.37,2.42)$ & 0.904 & $0.74(0.21,2.6)$ & 0.634 \\
\hline & Hila & $1.45(0.49,4.31)$ & 0.499 & $1.88(0.42,8.39)$ & 0.41 \\
\hline
\end{tabular}

Table 5. Factors associated with parental care-seeking practices towards EIs in children

\begin{tabular}{|c|c|c|c|c|c|}
\hline \multicolumn{2}{|c|}{ Care-seeking practice } & \multicolumn{2}{|l|}{ Crude } & \multicolumn{2}{|l|}{ Adjusted } \\
\hline & & OR $(95 \% \mathrm{CI})$ & $\mathrm{p}$ value & OR $(95 \% \mathrm{CI})$ & $\mathrm{p}$ value \\
\hline \multirow[t]{3}{*}{ Age } & $<30$ years old & 1 & & 1 & \\
\hline & $30-40$ years old & $0.46(0.09,2.28)$ & 0.341 & $0.3(0.05,1.64)$ & 0.164 \\
\hline & $>40$ years old & $2.23(0.2,25.2)$ & 0.517 & $1.05(0.07,15)$ & 0.974 \\
\hline \multirow[t]{2}{*}{ Gender } & Male & 1 & & 1 & \\
\hline & Female & $0.95(0.26,3.47)$ & 0.942 & $2(3,4)$ & 0.997 \\
\hline \multirow[t]{2}{*}{ Marital status } & Living alone & 1 & & 1 & \\
\hline & Living with a spouse & $2(3,4)$ & 0.999 & $8.19(0.81,82.75)$ & 0.075 \\
\hline \multirow[t]{3}{*}{ Education } & Primary and below & 1 & & 1 & \\
\hline & Secondary & $0.26(0.03,2.21)$ & 0.217 & $3.39(0.34,33.4)$ & 0.296 \\
\hline & Tertiary & $1.91(0.17,21.72)$ & 0.601 & $14.96(1.12,28.80)$ & 0.041 \\
\hline \multirow[t]{3}{*}{ Occupation } & Not working & 1 & & 1 & \\
\hline & Housewife & $0.32(0.04,2.76)$ & 0.3 & NA & 0.997 \\
\hline & Working & $1.06(0.11,10.53)$ & 0.958 & $1.1(0.1,11.73)$ & 0.939 \\
\hline \multirow[t]{3}{*}{ Smoking } & Non-smoker & & & & \\
\hline & Former smoker & $0.38(0.04,3.38)$ & 0.384 & $0.2(0.01,3.18)$ & 0.253 \\
\hline & Current smoker & $0.59(0.12,2.95)$ & 0.518 & $0.85(0.08,8.98)$ & 0.852 \\
\hline \multirow[t]{3}{*}{ Income } & Below average & 1 & & 1 & \\
\hline & Average & $2.59(0.5,13.35)$ & 0.256 & $1.88(0.31,11.25)$ & 0.491 \\
\hline & Above average & $3.68(0.31,43.32)$ & 0.3 & $0.55(0.02,16.19)$ & 0.729 \\
\hline \multicolumn{2}{|c|}{ Number of children below 10 years } & $0.79(0.46,1.35)$ & 0.389 & $0.86(0.44,1.68)$ & 0.667 \\
\hline \multirow[t]{2}{*}{ Car possession } & No & 1 & & 1 & \\
\hline & Yes & $2.74(0.65,8.67)$ & 0.189 & $1.33(0.26,6.91)$ & 0.732 \\
\hline
\end{tabular}

Respondents with tertiary education had higher odds of having satisfactory knowledge (OR 4.63, 95\% CI 1.18-18.19) and proper care-seeking practices (OR 14.96, 95\% CI 1.12-28.80) compared to those with primary education and below. Former smokers had lower odds of having satisfactory knowledge compared to non-smokers (OR $0.12,95 \%$ CI 0.02-0.70) (Table 4 and 5). It has previously been found that female gender was associated with better knowledge about childhood EI [22]. At the same time, younger 
people reported more frequent care-seeking practices [23]. Contradictory to published reports, gender and age were not associated with knowledge or care-seeking practices in this study.

Following the recent research findings, we expected that parents with low income would be less likely to seek proper health care [15], [18]. However, it was not evident in our results which might be attributed to the cost of healthcare in Iraq being affordable to the populations with different income status. So, the impact of income status on care-seeking behavior was not notable, which goes in line with other reports [13], [24]. Previous literature revealed that educational level was associated with both knowledge and care-seeking practices [18], [24]. Consistently, in our study, the respondents with higher education demonstrated better knowledge of the risk of EI complications and hence, were more likely to adopt proper care-seeking practices. Regarding the importance of education in improving health, maternal educational level was found to be associated with a range of health behaviors, including care-seeking practices and adequate child care [25]. World Health Organization advocates for improving women educational status, arguing that raising education rates for women would help to improve a wide range of health outcomes [26].

Although parental smoking has been reported to be a risk factor for childhood EI [27], as far as we know, no previous research has investigated the association between parental smoking and knowledge about EI in children. We found that former smokers had significantly lower levels of knowledge about childhood EI compared to those who had never smoked. Parental smoking might reflect their health ignorance. A few studies have shown a relationship between smoking status and a low-quality diet [28], [29]. Besides, limited health literacy was reported to be associated with being a smoker [30].

\section{CONCLUSION}

Respondents had satisfactory parental knowledge and care-seeking practices toward childhood EI. Educational level was associated with higher knowledge and care-seeking practices, and former smoking status was associated with lower knowledge.

Even though we have made the necessary steps to report generalizable results, some limitations were inevitable. The study included the hospitals in major cities; therefore, patients from rural areas might not have been well captured. Parents who are attending hospitals are likely to be more educated than those attending primary care clinics. Finally, we were not able to retrieve information about the frequency of EI among children, which might have provided some insight into the level of parental exposure to childhood EIs. Further study is suggested with larger area including rural areas.

\section{ACKNOWLEDGEMENTS}

The authors would like to thank all participants who provided timely response. The authors would like to thank Associate Professor Dr. Halyna Lugova from National Defence University of Malaysia for editing the manuscript.

\section{REFERENCES}

[1] G. Stevens, S. Flaxman, E. Brunskill, M. Mascarenhas, C. D. Mathers, and M. Finucane, "Global and regional hearing impairment prevalence: An analysis of 42 studies in 29 countries," European Journal of Public Health, vol. 23, no. 1, pp. 146-152, Feb. 2013, doi: 10.1093/eurpub/ckr176.

[2] L. Monasta et al., "Burden of disease caused by otitis media: systematic review and global estimates," PLoS ONE, vol. 7, no. 4, p. e36226, Apr. 2012, doi: 10.1371/journal.pone.0036226.

[3] C. Paltura, T. S. Can, B. K. Yilmaz, M. E. Dinç, Ö. N. Develioğlu, and M. Külekçi, "Eustachian tube diameter: Is it associated with chronic otitis media development?," American Journal of Otolaryngology - Head and Neck Medicine and Surgery, vol. 38, no. 4, pp. 414-416, Jul. 2017, doi: 10.1016/j.amjoto.2017.03.012.

[4] S. Bakir et al., "Mental health and quality of life in patients with chronic otitis media," European Archives of Oto-RhinoLaryngology, vol. 270, no. 2, pp. 521-526, Feb. 2013, doi: 10.1007/s00405-012-2031-6.

[5] C. N. M. Brouwer, A. R. Maillé, M. M. Rovers, D. E. Grobbee, E. A. M. Sanders, and A. G. M. Schilder, "Health-related quality of life in children with otitis media," International Journal of Pediatric Otorhinolaryngology, vol. 69, no. 8, pp. 1031-1041, Aug. 2005, doi: 10.1016/j.ijporl.2005.03.013.

[6] M. A. Kenna, “Acquired Hearing Loss in Children," Otolaryngologic Clinics of North America, vol. 48, no. 6, pp. 933-953, Dec. 2015, doi: 10.1016/j.otc.2015.07.011.

[7] V. Yiengprugsawan and A. Hogan, "Ear infection and its associated risk factors, comorbidity, and health service use in Australian children," International Journal of Pediatrics, vol. 2013, pp. 1-7, 2013, doi: 10.1155/2013/963132.

[8] F. Martines, D. Bentivegna, E. Maira, V. Sciacca, and E. Martines, "Risk factors for otitis media with effusion: case-control study in Sicilian schoolchildren," International Journal of Pediatric Otorhinolaryngology, vol. 75, no. 6, pp. 754-759, Jun. 2011, doi: 10.1016/j.ijporl.2011.01.031.

[9] L. L. Jones, A. Hassanien, D. G. Cook, J. Britton, and J. Leonardi-Bee, "Parental smoking and the risk of middle ear disease in children: A systematic review and meta-analysis," Archives of Pediatrics and Adolescent Medicine, vol. 166, no. 1, pp. 18-27, Jan. 2012, doi: 10.1001/archpediatrics.2011.158.

[10] J. Jervis-Bardy, L. Sanchez, and A. S. Carney, "Otitis media in indigenous australian children: review of epidemiology and risk 
factors," Journal of Laryngology and Otology, vol. 128, no. SUPPL.S1, pp. S16-S27, Jan. 2014, doi: 10.1017/S0022215113003083.

[11] Y. Zhang, M. Xu, J. Zhang, L. Zeng, Y. Wang, and Q. Y. Zheng, "Risk factors for chronic and recurrent otitis media-A metaanalysis," PLOS ONE, vol. 9, no. 1, p. e86397, Jan. 2014, doi: 10.1371/journal.pone.0086397.

[12] S. B. Amutta et al., "Sociodemographic characteristics and prevalence of self ear cleaning in sokoto metropolis," International Journal of Otolaryngology and Head \&amp; Neck Surgery, vol. 02, no. 06, pp. 276-279, 2013, doi: 10.4236/ijohns.2013.26057.

[13] L. K. Qasim, Y. S. Bayunus, F. A. Alzubaidi, S. H. ALyami, and N. K. I. AlOsaimi, "Knowledge, attitude and practices towards otitis media in saudi arabia community," The Egyptian Journal of Hospital Medicine, vol. 69, no. 6, pp. 2552-2556, Oct. 2017, doi: $10.12816 / 0042229$.

[14] J. P. D. Nshimirimana and K. B. Mukara, "Causes of delayed care seeking for chronic suppurative otitis media at a Rwandan Tertiary Hospital,” International Journal of Otolaryngology, vol. 2018, pp. 1-5, Jul. 2018, doi: 10.1155/2018/5386217.

[15] I. Villarreal et al., "Healthcare-seeking behaviour of primary caregivers for acute otitis media in children aged 6 months to <30 months in Panama: Results of a cross-sectional survey," BMC Pediatrics, vol. 17, no. 1, p. 3, Dec. 2017, doi: 10.1186/s12887016-0760-1.

[16] N. F. Poole, M. K. Skilton, T. C. P. Martin, and M. C. F. Smith, "Knowledge, attitudes, beliefs and practices related to chronic suppurative otitis media and hearing impairment in Pokhara, Nepal," Journal of Laryngology and Otology, vol. 130, no. 1, pp. 56-65, Jan. 2016, doi: 10.1017/S0022215115002996

[17] M. M. Alharbi, M. S. Almasri, A. Y. Aldayel, and S. M. Alkhonezan, "Parental knowledge, attitudes and practices towards paediatric ear infections in Riyadh, Saudi Arabia a quantitative study," Sultan Qaboos University Medical Journal, vol. 19, no. 2, pp. e114-e121, Sep. 2019, doi: 10.18295/squmj.2019.19.02.006.

[18] A. A. Adeyemo, "Knowledge of caregivers on the risk factors of otitis media," Indian Journal of Otology, vol. 18, no. 4, pp. 184188, 2012, doi: 10.4103/0971-7749.104795.

[19] L. Anselmi, M. Lagarde, and K. Hanson, "Health service availability and health seeking behaviour in resource poor settings: evidence from Mozambique," Health Economics Review, vol. 5, no. 1, p. 26, Dec. 2015, doi: 10.1186/s13561-015-0062-6.

[20] A. Llop-Gironés et al., "Inequalities in the access to and quality of healthcare in Mozambique: evidence from the household budget survey," International Journal for Quality in Health Care, vol. 31, no. 8, pp. 577-582, Nov. 2019, doi: 10.1093/intqhc/mzy218.

[21] S. Rawaf et al., "Living conditions in Iraq: 10 years after the US-led invasion," Journal of the Royal Society of Medicine, vol. 107, no. 5, pp. 187-193, May 2014, doi: 10.1177/0141076814530684.

[22] F. Di Berardino, S. Forti, E. Iacona, G. P. Orlandi, U. Ambrosetti, and A. Cesarani, "Public awareness of ear and hearing management as measured using a specific questionnaire," European Archives of Oto-Rhino-Laryngology, vol. 270, no. 2, pp. 449453, Feb. 2013, doi: 10.1007/s00405-012-1961-3.

[23] A. M. Irwan, M. Kato, K. Kitaoka, T. Kido, Y. Taniguchi, and M. Shogenji, "Self-care practices and health-seeking behavior among older persons in a developing country: Theories-based research," International Journal of Nursing Sciences, vol. 3, no. 1, pp. 11-23, Mar. 2016, doi: 10.1016/j.ijnss.2016.02.010.

[24] K. B. Mukara, P. Waiswa, R. Lilford, and D. L. Tucci, "Knowledge and care seeking practices for ear infections among parents of under five children in Kigali, Rwanda: A cross-sectional study," BMC Ear, Nose and Throat Disorders, vol. 17, no. 1, p. 7, Dec. 2017, doi: 10.1186/s12901-017-0040-1.

[25] B. S. Mensch, E. K. Chuang, A. J. Melnikas, and S. R. Psaki, "Evidence for causal links between education and maternal and child health: systematic review," Tropical Medicine and International Health, vol. 24, no. 5, pp. 504-522, May 2019, doi: $10.1111 /$ tmi.13218.

[26] S. Kuruvilla et al., “The Global strategy for women's, children's and adolescents' health (2016-2030): a roadmap based on evidence and country experience," Bulletin of the World Health Organization, vol. 94, no. 5, pp. 398-400, May 2016, doi: 10.2471/BLT.16.170431.

[27] M. A. Moreno, F. Furtner, and F. P. Rivara, "Parental smoking and childhood ear infections: A dangerous combination," Archives of Pediatrics and Adolescent Medicine, vol. 166, no. 1, p. 104, Jan. 2012, doi: 10.1001/archpedi.166.1.104.

[28] A. Alkerwi et al., "Smoking status is inversely associated with overall diet quality: Findings from the ORISCAV-LUX study," Clinical Nutrition, vol. 36, no. 5, pp. 1275-1282, Oct. 2017, doi: 10.1016/j.clnu.2016.08.013.

[29] S. K. Raatz et al., "Smokers report lower intake of key nutrients than nonsmokers, yet both fall short of meeting recommended intakes," Nutrition Research, vol. 45, pp. 30-37, Sep. 2017, doi: 10.1016/j.nutres.2017.07.010.

[30] C. Fawns-Ritchie, J. M. Starr, and I. J. Deary, "Health literacy, cognitive ability and smoking: a cross-sectional analysis of the english longitudinal study of ageing," BMJ Open, vol. 8, no. 10, p. e023929, Oct. 2018, doi: 10.1136/bmjopen-2018-023929. 